\title{
Farhat J. Ziadeh
}

\section{Property Law in the Arab World \\ Real Rights in Egypt, Iraq, Jordan, Lebanon, Libya, Syria, Saudi Arabia and die Gulf States}

Graham \& Trotman Ltd., London, 1979, 113 S.

Ziadeh stellt die Eigentumsrechte an Grundstücken auf den 113 Seiten seines Buches nicht erschöpfend dar, sondern greift Gebiete heraus, die seiner Meinung nach den Rechtsvergleicher ebenso interessieren wie den Kaufmann, der im Nahen und Mittleren Osten tätig ist. Bedauerlicherweise fehlt dem Buch, dessen einzelne Kapitel mit unzähligen Fußnoten versehen sind, ein Annex, das den übersetzten Text der jeweiligen Codices wiedergibt. Der Verweis auf einen bestimmten Artikel des z. B. ägyptischen Code civil gewinnt erst dann an Inhalt, wenn der Leser den Text der Vorschrift mit der vom Verfasser wiedergegebenen Praxis vergleichen kann - oder soll der Leser sich der mühseligen und oft ergebnislosen Suche nach dem jeweiligen Gesetzestext selbst unterziehen?

Davon abgesehen besticht das Buch durch seine dem europäischen Juristen durchaus vertraute, systematische Gliederung. Der Verfasser stellt die historische Entwicklung des modernen Eigentumsbegriffs, wie er heute im Orient verstanden wird, an den Anfang. Er erklärt u. a., daß der Grund und Boden in der arabischen Welt danach eingeteilt wurde, welche Art von Abgaben für ihn zu entrichten waren, daß es per definitionem für dieses Rechtsgebiet keinen abstrakten Eigentumsbegriff gegeben hat, sondern eher ein Abgabenrecht, aus welchem sich die unterschiedlichen Rechte an einem Stück Land herleiteten. - Diesem rund 1/3 des Buches einnehmenden historischen Abriß folgt eine detaillierte Darstellung über die Erlangung von Grundeigentum - durch Urbarmachung von Odland, durch Vertrag unter Lebenden, wobei der Registrierung des Eigentumswechsels in den einzelnen Ländern unterschiedliche Bedeutung zukommt, teils besitzt sie konstitutive Wirkung für den Eigentumsübergang, teils wird sie bereits als unabdingbare Wirksamkeitsvorraussetzung für den den Eigentumsübergang versprechenden Vertrag verstanden, und natürlich durch Rechtsnachfolge im Wege des Erbgangs. Es gibt (noch) das Vorkaufsrecht, das an praktischer Bedeutung verliert (in Syrien ist es abgeschafft, im Iraq ist es nur innerhalb eines Zeitraumes von 6 Monaten nach Eintritt des Vorkaufsfalls ausübbar, und diese Frist gilt auch, wenn der Berechtigte von dem Eintritt des Vorkaufsfalls keine Kenntnis erlangt). Auch der Erwerb des Eigentums durch Ersitzung (hiyazah) ist nicht unbekannt; als Kuriosum ist in diesem Zusammenhang zu erwähnen, daß nach ägyptischem und syrischem Recht der bösgläubige Grundbesitzer nach 15 Jahren Eigentum erlangt, der gutgläubige schon nach 5 Jahren.

Die vom Eigentum abgeleiteten Rechte sind teilweise dem Islam eigentümliche Rechtsfiguren - man denke an tasarruf, ein Recht, das dem Eigentum nahezu angeglichen ist, aber miri-Land betrifft, und an hikr, die Nutznießung von waqf-Eigentum, dessen Bedeutung mehr und mehr zurückgeht - teilweise sind sie aus der Rezeption europäischen Rechts entstanden wie dinglicher Nießbrauch und Dienstbarkeiten. In diesem Zusammenhang sind Wege- und Wasserrechte zu nennen, die hier durch vertragliche Vereinba- 
rung begründet und nicht - woran man denken könnte - aus der Sozialgebundenheit des Eigentums hergeleitet werden.

Grundpfandrechte sind nach den Ausführungen des Verfassers offenbar nur in der Form der Verknüpfung von persönlicher Schuld und dinglicher Sicherheit bekannt; anscheinend sind nichtakzessorische Rechte wie die Grundschuld nicht existent.

Das Buch schließt mit einem Kapitel über Neuerungen im Immobiliarrecht, es erläutert die großen Landreformen in Ägypten, Syrien und im Iraq. Ein Anhang geht summarisch auf die Rechtslage in Saudi-Arabien und in den Golfstaaten ein und weist die allerdings sehr begrenzten Möglichkeiten für Ausländer auf, Grundeigentum zu erwerben.

Dagmar Hohberger

\section{Hasan Moinuddin}

Die Organisation der Islamischen Konferenz (OIC) als Forum politischer und wirtschaftlicher Kooperation

Studienverlag Brookmeyer, Sozialwissenschaftliche Studien, Bd. 24, Bochum, 1984, 214 S., DM 29,80

1969 wurde in Rabat auf der ersten islamischen Gipfelkonferenz die Organisation der Islamischen Konferenz (OIC) gegründet, deren Charta 1973 in Kraft trat.

In seiner 1984 vorgelegten Dissertation arbeitet Hasan Moinuddin die Charakteristika dieser Organisation heraus, wobei er insbesondere untersucht, inwieweit die universalen Grundsätze des Völkerrechts beachtet werden. Hierbei kommt er zu dem Ergebnis, daß die Prinzipien Souveränität, Gleichheit der Staaten, Selbstbestimmung und Interventionsverbot, friedliche Streitbeilegung sowie Gewaltverbot anerkannt werden, obwohl sie zum Teil zur klassischen Djihaddoktrin in Widerspruch stehen. Während seine Darstellung der Djihaddoktrin und ihre Bedeutung bzw. Abwandlung in der Gegenwart gelungen ist, finden sich bei der Behandlung der völkerrechtlichen Prinzipien doch manche Ungenauigkeiten (so etwa bei der Erörterung des Gleichheitssatzes und seinen Auswirkungen auf die Entscheidungsfindung S. 49 ff.).

In weiten Passagen des Werks erörtert der Verfasser die einzelnen Bestimmungen der Charta. Dies geschieht jedoch sehr oberflächlich und stellt oftmals nur eine Wiedergabe des Textes dar. Eingegangen wird auf das Problem, welcher Staat als wislamischer Staat" zu verstehen ist. Der Entwurf der Charta sah eine Differenzierung zwischen Vollmitgliedschaft und Teilnehmerstatus vor. Die Charta in der ratifizierten Form trifft diese Unterscheidung nicht mehr, vielmehr besteht die Möglichkeit, beim Beitritt einen Vorbehalt zu erklären. Zur Zeit gehören 44 Staaten der OIC an.

Eine Bewertung der OIC ist angesichts der geringen praktischen Aktivität schwierig. So fanden nach Inkrafttreten der Charta lediglich 1974 in Lahore, 1981 in Mekka und 1984 in Casablanca Gipfelkonferenzen statt. Es wurde nunmehr vereinbart, jeweils Gipfelkonferenzen im 3-Jahres-Turnus abzuhalten. 